\title{
Stress Changes on the Garlock Fault during and after the 2019 Ridgecrest Earthquake Sequence
}

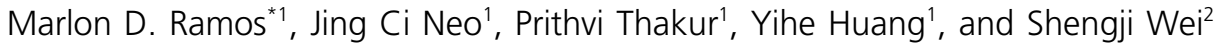

\begin{abstract}
The recent 2019 Ridgecrest earthquake sequence in southern California jostled the seismological community by revealing a complex and cascading foreshock series that culminated in a $M_{\mathrm{w}} 7.1$ mainshock. But the central Garlock fault, despite being located immediately south of this sequence, did not coseismically fail. Instead, the Garlock fault underwent postseismic creep and exhibited a sizeable earthquake swarm. The dynamic details of the rupture process during the mainshock are largely unknown, as is the amount of stress needed to bring the Garlock fault to failure. We present an integrated view of how stresses changed on the Garlock fault during and after the mainshock using a combination of tools including kinematic slip inversion, Coulomb stress change ( $\triangle \mathrm{CFS}$ ), and dynamic rupture modeling. We show that positive $\Delta$ CFSs cannot easily explain observed aftershock patterns on the Garlock fault but are consistent with where creep was documented on the central Garlock fault section. Our dynamic model is able to reproduce the main slip asperities and kinematically estimated rupture speeds ( $\leq 2 \mathrm{~km} / \mathrm{s}$ ) during the mainshock, and suggests the temporal changes in normal and shear stress on the Garlock fault were the greatest near the end of rupture. The largest static and dynamic stress changes on the Garlock fault we observe from our models coincide with the creeping region, suggesting that positive stress perturbations could have caused this during or after the mainshock rupture. This analysis of near-field stress-change evolution gives insight into how the Ridgecrest sequence influenced the local stress field of the northernmost eastern California shear zone.
\end{abstract}

\section{KEY POINTS}

- We examine stress changes on the Garlock fault during and after the Ridgecrest sequence.

- Our models reproduce mainshock characteristics and document temporal stress change on the Garlock fault.

- Results show influence of the Ridgecrest sequence on near-field stresses in the eastern California shear zone.

Supplemental Material

\section{INTRODUCTION}

The 2019 Ridgecrest earthquake sequence involved the rupture of a left-lateral $M_{\mathrm{w}} 6.4$ foreshock that occurred on 4 July and a right-lateral $M_{\mathrm{w}} 7.1$ mainshock that occurred on 6 July and initiated approximately $13 \mathrm{~km}$ northwest of the foreshock epicenter (Fig. 1a). This sequence was characterized by the activation of multiple orthogonal fault segments that are collectively referred to as the Little Lake fault zone (Llfz). Coseismic rupture of these faults continues to produce aftershocks, but it did not influence the adjacent left-lateral Garlock fault to fail. Instead, this sequence caused as much as three centimeters of surface creep on the Garlock fault that has been detected geodetically (Barnhart et al., 2019; Ross et al., 2019).

Several kinematic slip models have been developed to estimate the evolution of slip and rupture propagation during this highly complex sequence (Barnhart et al., 2019; Liu et al., 2019; Ross et al., 2019; Chen et al., 2020; Goldberg et al., 2020; Zhang et al., 2020). These models are consistent in the respect that a majority of foreshock and mainshock slip is limited to the upper $10 \mathrm{~km}$ depth. Positive stress-change amplitudes ( 0.5 MPa) suggested by static Coulomb modeling generally coincide with the $\sim 25$-kilometer-long region of creep on the central Garlock fault segment (Barnhart et al., 2019). But the dynamic details of rupture and how stresses were mediated by the seismic wavefield remain hazy. The Garlock fault was apparently not near critical failure, or else we would have observed coseismic rupture there as well; this implies that the stress perturbations were unable to

\footnotetext{
1. Department of Earth and Environmental Sciences, University of Michigan, Ann Arbor, Michigan, U.S.A.; 2. Earth Observatory of Singapore, Nanyang Technological University, Singapore, Singapore

*Corresponding author: ramosmd@umich.edu

Cite this article as Ramos, M. D., J. C. Neo, P. Thakur, Y. Huang, and S. Wei (2020) Stress Changes on the Garlock Fault during and after the 2019 Ridgecrest Earthquake Sequence, Bull. Seismol. Soc. Am. XX, 1-13, doi: 10.1785/0120200027

(C) Seismological Society of America
} 
(a)

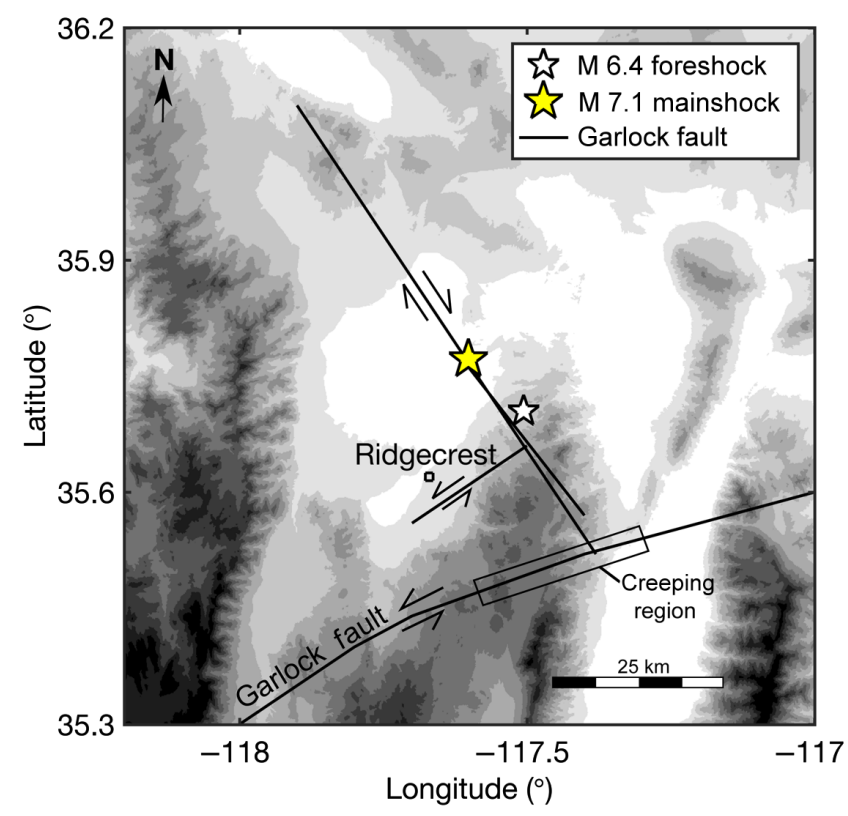

(b)

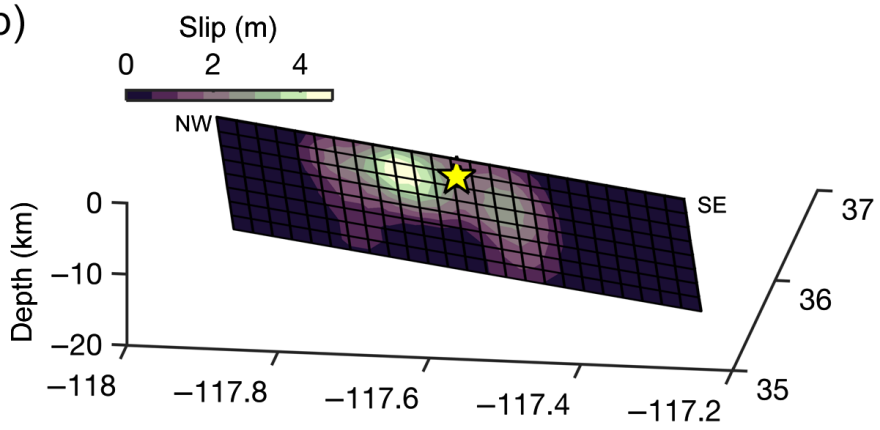

(c)

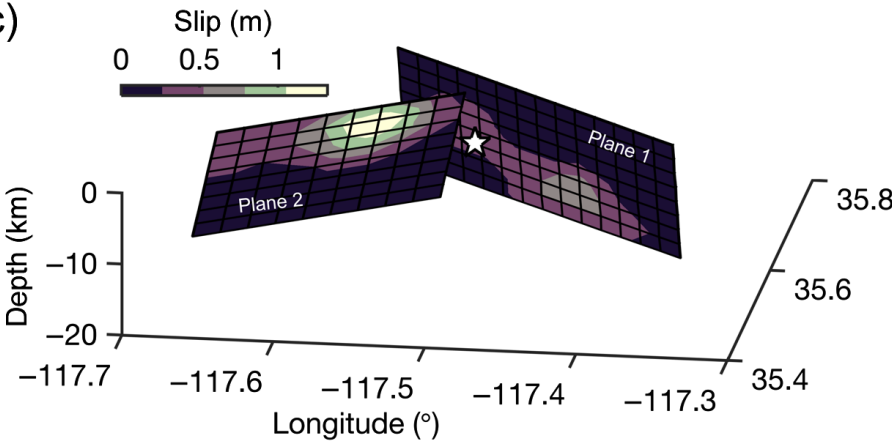

bring shear stresses to overcome the static Garlock fault strength.

When the Garlock fault will slip again is a major unknown. The Garlock fault extends for $\sim 260 \mathrm{~km}$ and is geometrically segmented into western, central, and eastern sections that are characterized by variations in geologic slip rate and recurrence interval (Hill and Dibblee, 1953; Davis and Burchfiel, 1973; McGill and Sieh, 1991). Astiz and Allen (1983) analyzed historical seismicity on this fault and hypothesized that a rupture on the eastern Garlock segment may be more likely given its apparent seismic gap, though both the central and western sections can independently support $M_{\mathrm{w}} \sim 7$ earthquakes. Paleoseismic evidence suggests historic, nonperiodic surface rupture for the central Garlock segment (Dawson et al., 2003). During the Ridgecrest sequence, different regions of the central Garlock fault segment experienced a swarm of low-magnitude earthquakes $\left(M_{\mathrm{L}}<3.2\right.$; Ross et al., 2019) and underwent creep. How the strain accumulation budget of the central Garlock fault was influenced by the recent Ridgecrest sequence is enigmatic and warrants further scrutiny for seismic hazard analysis. A spatial separation between the Ridgecrest mainshock and Garlock fault planes is furthermore subject to uncertainty, as is the possibility of rupture branching from a segment of the Garlock fault onto an adjacent segment or to the San Andreas fault during a future earthquake. In particular, the central and western segments have coruptured within the last $10 \mathrm{ka}$, despite a stepover structure in between them (Madugo et al., 2012). Assessing the possibility of how close the Garlock fault is to failure depends on both the static and dynamic stress perturbations from the Ridgecrest sequence.
Figure 1. 2019 Ridgecrest earthquake sequence. (a) Study area with foreshock and mainshock fault planes denoted by solid lines. The approximate region of the central Garlock fault that experienced creep during this sequence is indicated by the box. (b) Mainshock slip-inversion results in which we determine a hypocenter depth of $3 \mathrm{~km}$ and a peak slip amplitude of $4.7 \mathrm{~m}$ that is immediately northwest (NW) of the hypocenter.

(c) Foreshock slip-inversion results. Foreshock planes parallel and perpendicular to the mainshock fault plane are denoted as plane 1 and plane 2, respectively. Note that an NW-southeast (SE) fault orientation is the same for the mainshock and foreshock fault planes. Stars indicate (a) epicenter or $(b, c)$ hypocenter locations. The color version of this figure is available only in the electronic edition.

We aim to present a physically consistent picture of the stress interaction vis-à-vis the Garlock fault during and after the Ridgecrest sequence. We draw from updated kinematic inversion results that utilize geodetic, teleseismic, and near-field strong ground motion recordings to independently constrain the faultslip amplitude, extent, and rupture initiation locations of the foreshocks and $M_{\mathrm{w}} 7.1$ mainshock. This is then used to inform our static Coulomb stress analysis and dynamic rupture modeling efforts. Our analysis illustrates that both normal and shear stress changes were the highest on the Garlock fault at the end of mainshock rupture, and could have been responsible for the observed geodetic creep as soon as $\sim 30 \mathrm{~s}$ from mainshock rupture initiation.

\section{METHODOLOGY Kinematic slip inversion}

We use a joint slip-inversion model that is based on static Global Positioning System (GPS), teleseismic, and local strong 
TABLE 1

Coulomb Stress-Change Parameters of the Mainshock and Aftershock Fault Planes

\begin{tabular}{lllllc}
\hline Event & $\mathbf{M}_{\mathbf{w}}$ & Hypocenter & Strike & Dip & Rake \\
Mainshock & 7.1 & $35.772^{\circ} \mathrm{N},-117.602^{\circ} \mathrm{E}, 3 \mathrm{~km}$ & 322 & 81 & -170 \\
Foreshock & 6.4 & $35.705^{\circ} \mathrm{N},-117.506^{\circ} \mathrm{E}, 9 \mathrm{~km}$ & 318 & 88 & -172 \\
& & & 228 & 81 & 0 \\
\hline
\end{tabular}

Hypocenter location (latitude, longitude, and depth) and maximum slip amplitude (meters) from the kinematic inversion are also listed.

ground motion datasets (Ji et al., 2002). The $M_{\mathrm{w}} 6.4$ foreshock and the $M_{\mathrm{w}} 7.1$ mainshock are modeled with two- and singlefault plane geometries, respectively (Fig. 1). Slip along the mainshock fault occurs along a 100-kilometer-long segment that dips at $\sim 88^{\circ}$ (Fig. 1b). Of the two foreshock fault planes, one is nearly parallel to the strike of the mainshock (plane 1), whereas the second is perpendicular to the mainshock (plane 2; Fig. 1c; Table 1). These fault plane geometries are consistent with those estimated by the U.S. Geological Survey and do not extend deeper than $16 \mathrm{~km}$ depth. Geologic mapping and Interferometric Synthetic Aperture Radar (InSAR) observations of surface-breaching rupture strands during the Ridgecrest sequence suggest that our geometries are reasonable (Xu et al., 2020, and references therein). We use the slip-inversion results for the foreshock and mainshock fault planes as input into our static and dynamic stress-change modeling.

\section{Static model: Coulomb stress change}

Static stress changes are the final changes in the normal and shear stresses on the fault in response to slip after all seismic waves have propagated through. Such stress changes during the foreshock and mainshock of the Ridgecrest sequence have triggered thousands of aftershocks (Ross et al., 2019). Coseismic stress changes have also been known to enhance or to reduce creep after the earthquake (e.g., Allen et al., 1972; Bodin and Gomberg, 1994; Lienkaemper et al., 1997). Barnhart et al. (2019) observed that an increase in the Coulomb stress change ( $\triangle \mathrm{CFS}$ ) from the Ridgecrest earthquake was correlated with the surface deformation after the earthquake. Studies have also suggested that the $M_{\mathrm{w}} 6.4$ foreshock and other large foreshocks promoted the rupture of the mainshock (Barnhart et al., 2019; Goldberg et al., 2020; Lozos and Harris, 2020).

To assess static stress changes, we calculate the $\Delta$ CFS using the Coulomb 3 software (Lin and Stein, 2004; Toda et al., 2005). We investigate the $\Delta$ CFS caused by the foreshock on the mainshock and separate the contribution of stress change from each of the two foreshock fault planes (Plane 1 and Plane 2; Fig. 2). We use a friction coefficient of 0.6 and a depth of $5 \mathrm{~km}$ for the foreshock-mainshock static stress-change calculation because a majority of slip is resolved on foreshock plane 2 (Fig. 1c), which will dominate the $\Delta$ CFS amplitude.

We also calculate the $\Delta$ CFS due to mainshock slip on the Garlock fault. We represent the Garlock fault geometry as a plane with a strike, dip, and rake of $70^{\circ}, 90^{\circ}$, and $0^{\circ}$, respectively.
The strike of the Garlock fault varies from $68^{\circ}$ in the east to $84^{\circ}$ in the west (Fig. 3), but we use $70^{\circ}$ for the receiver fault as it is the closest to the strike of the western Garlock fault segment where the cluster of aftershocks occurred. Lastly, to address uncertainty in static friction level and hypocenter depth, we also examine how varying these parameters influences our results. We compare the results from friction coefficients of $0.2,0.4$, and 0.6 , and at $5 \mathrm{~km}$ depth, where peak slip occurred, and at $10 \mathrm{~km}$ depth, where the asperity with most slip extends.

\section{Dynamic model: Initial conditions and constraints}

We model the mainshock fault plane as a $100 \mathrm{~km}$, planar 2D crack embedded in a homogeneous, isotropic, and linearly elastic medium with a shear wavespeed of $3.2 \mathrm{~km} / \mathrm{s}$. The model domain is composed of rectangular elements enclosed on all sides by absorbing boundaries (Fig. S1, available in the supplemental material to this article). We choose a finite-element size of $600 \mathrm{~m}$ with four Gauss-Lobatto-Legendre nodes to resolve dynamic rupture propagation at seismic frequencies up to $1 \mathrm{~Hz}$ for consistency with that resolved by the strong-motion dataset.

We select the linear slip-weakening friction law to control fault-slip evolution and utilize the $2 \mathrm{D}$ spectral element code SEM2DPACK to solve for dynamic rupture propagation (Ampuero, 2009). The critical-slip distance $\left(D_{c}\right)$ is $0.3 \mathrm{~m}$, which is constant along the fault (except for $\sim 15 \mathrm{~km}$ around the nucleation region) and is within the plausible range of previous slipweakening dynamic rupture simulations for other crustal earthquakes of comparable magnitude and rupture dimension (e.g., Ma and Archuleta, 2006; Tinti et al., 2009; Lozos and Harris, 2020). If dynamic friction $\left(\mu_{d}\right)$ is below the static friction $\left(\mu_{s}\right)$ level, then the fault experiences a strength drop during coseismic rupture and its frictional behavior is slip weakening; conversely, if the dynamic friction is greater than static friction, there is no work available to grow the propagating shear crack and the frictional behavior is slip strengthening. The static friction coefficient is 0.5 everywhere along the fault. The fault is slip weakening $\left(\mu_{d}=0.1\right)$ along the central $70 \mathrm{~km}$ segment $(35 \mathrm{~km}$ southeast and northwest of hypocenter) and slip strengthening $\left(\mu_{d}=0.7\right)$ everywhere else to prohibit rupture from breaking the entire fault.

Given that we represent a strike-slip fault as a mode II in-plane crack, our stress and friction conditions are relative to a region on the mainshock fault plane at depth. Our model aims to reproduce 
(a)

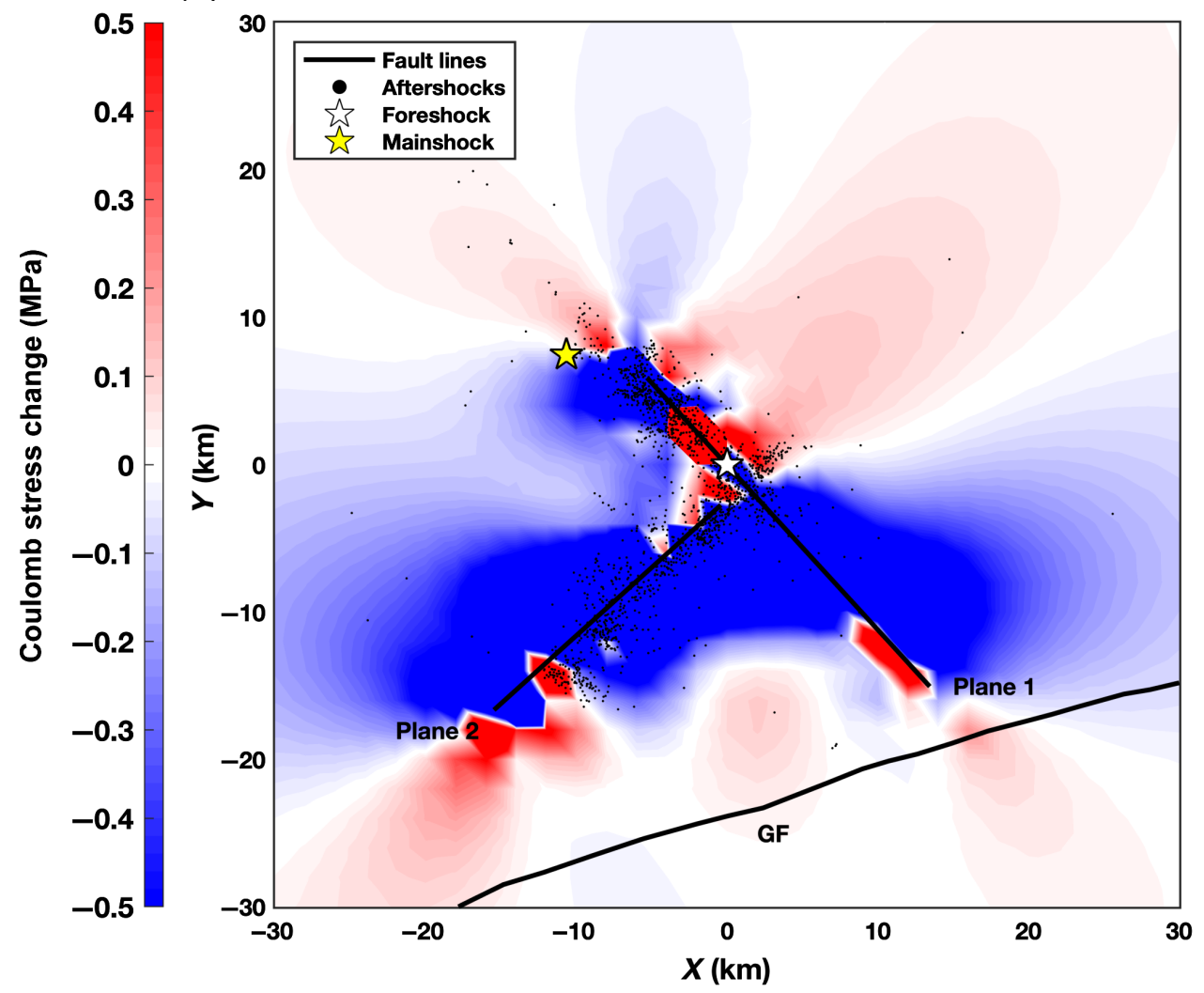

(b)

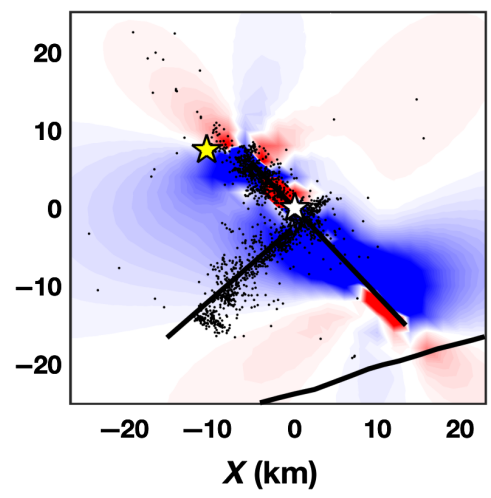

(c)

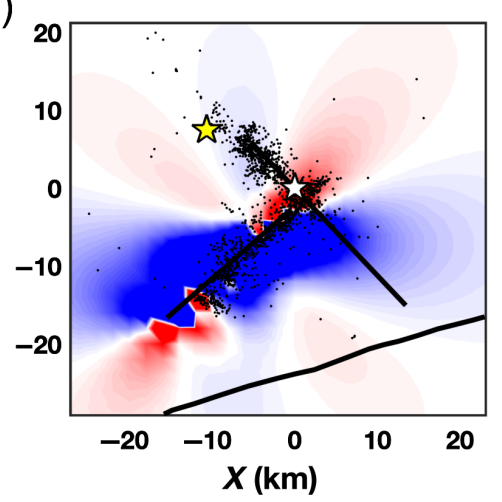

the rupture propagation along the section of the fault that crosses through the main slip asperity imaged in the kinematic inversion (Fig. 4). Effective normal stress is set to a constant level of $50 \mathrm{MPa}$ that is consistent with elevated pore-pressure levels in the middle of permeable fault zones (Rice, 1992).

The initial shear stress distribution is a critical ingredient for any dynamic earthquake rupture model and determines the dynamic stress drop which in turn governs slip amplitude. We first calculate the static stress drop due to fault slip given by the kinematic inversion using a computationally efficient algorithm (Fig. 4; Ripperger and Mai, 2004). Earthquakes can exhibit total or near-total stress drop due to strong dynamic weakening (e.g., Noda and Lapusta, 2013; Brodsky et al., 2020), meaning that the final shear stress on the fault after an earthquake is at or very near its dynamic fault strength level (the product of effective normal stress and dynamic friction). We make this assumption to calculate our initial shear stress by adding the static stress drop to the dynamic fault strength (Fig. 4).

Rupture is artificially nucleated in the middle of the fault using the time-weakening method (Andrews, 1985). This technique requires twice the critical half-crack length $\left(2 L_{c}\right)$, an effective friction level $\left(\mu_{0}\right)$, and a weakening timescale $\left(T_{c}\right)$ after which the prescribed nucleation is turned off and rupture spontaneously evolves according to the nonlinear interaction between fault strengths and stresses. Given the friction law parameters we assume for mode II rupture in an elastic domain, $2 L_{c}$ is given by
Figure 2. Coulomb stress change ( $\Delta$ CFS) due to foreshock planes 1 and 2 on the mainshock fault plane calculated at a depth of $5 \mathrm{~km}$ and with a friction coefficient of 0.6. (a) The combined effect of both aftershock fault plane slip on the mainshock. (b) The $\Delta$ CFS from plane 1, which is parallel to the main fault plane. (c) $\Delta$ CFS from plane 2, which is the northeast-southweststriking cross fault. The aftershocks depicted are the earthquakes that occurred after the foreshock and do not include those induced from mainshock stress changes. GF, Garlock fault. The color version of this figure is available only in the electronic edition.

$$
2 L_{c}=\frac{2}{1-v} \frac{G}{\pi} \frac{\tau_{s}-\tau_{d}}{\left(\tau_{0}-\tau_{d}\right)^{2}} D_{c}
$$

in which $G$ is the shear modulus (30 GPa), $v$ is the Poisson's ratio, $\tau_{s}$ is the static fault strength, $\tau_{d}$ is the dynamic fault strength, $\tau_{0}$ is the initial shear stress, and $\mu_{0}$ is the effective friction coefficient calculated as the ratio between initial shear and effective normal stress amplitudes at the hypocenter. We determined that a $2 L_{c}$ of $2 \mathrm{~km}\left(\mu_{0}\right.$ of $\left.\sim 0.1\right)$ and $T_{c}$ of $10 \mathrm{~s}$ are necessary to nucleate and sustain spontaneous rupture.

\section{RESULTS}

\section{Kinematic slip inversion}

Using our kinematic inversion methodology, the mainshock hypocenter has been relocated to a depth of $3 \mathrm{~km}$ by the arrival times of nearby strong-motion and broadband seismic stations (Fig. 1b). The aftershock hypocenter is deeper $(9 \mathrm{~km})$ and slip 

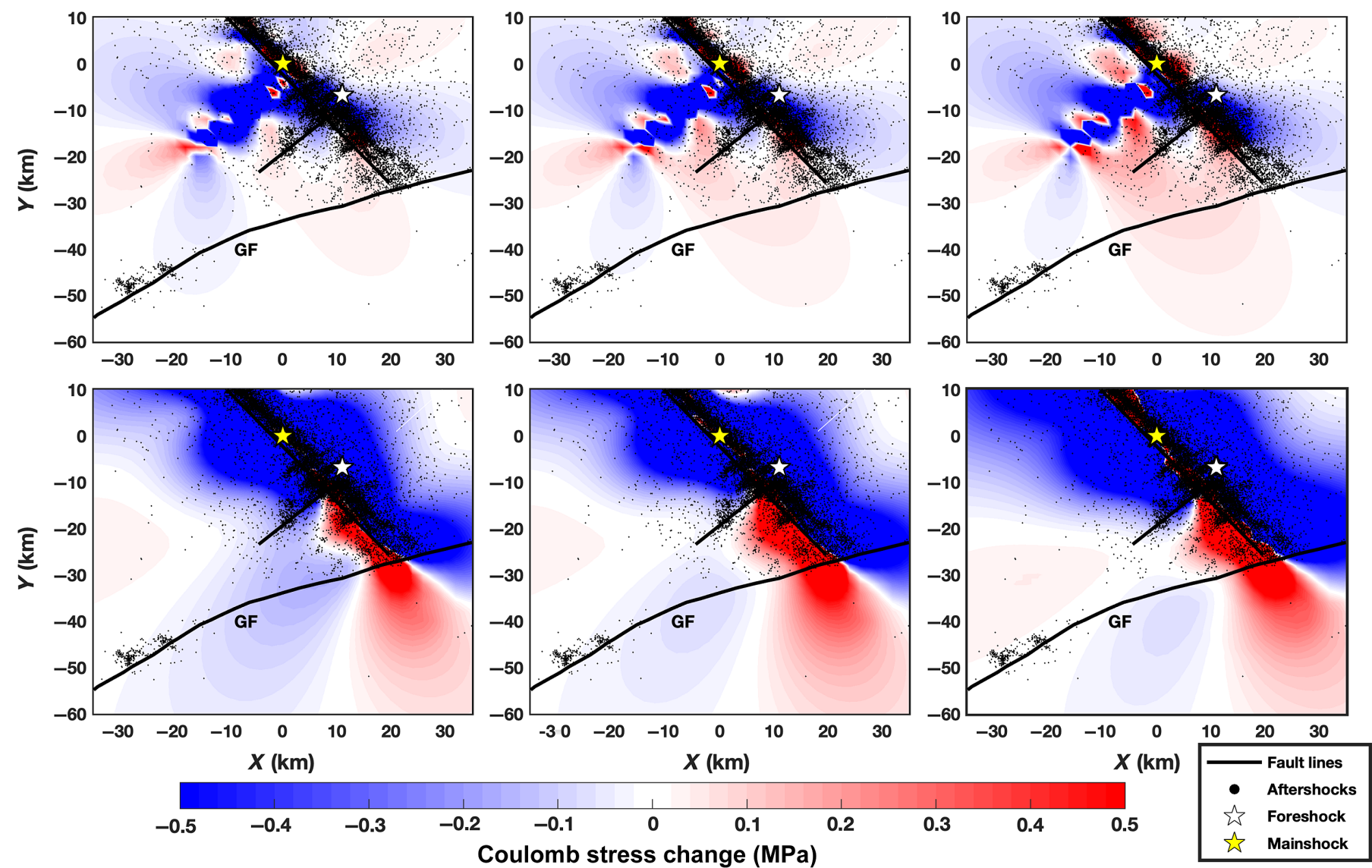

is distributed across two fault segments (Fig. 1c). The fault parameters and hypocenters of both earthquakes are summarized in Table 1. We note that the $M_{\mathrm{w}} 7.1$ mainshock ruptured bilaterally with a majority of slip concentrated within the upper $10 \mathrm{~km}$ and a peak slip amplitude of 4.7 m located $\sim 10 \mathrm{~km}$ northwest of the hypocenter (Fig. 1b). There is a smaller asperity that underwent $\sim 2.5 \mathrm{~m}$ of slip southeast of the mainshock hypocenter, as well. On the other hand, peak slip resolved for the foreshock is lower $(1.3 \mathrm{~m})$ and occurred mostly on plane 2 , which is perpendicular to the mainshock fault plane (Fig. 1c).

We also compare our mainshock slip-inversion results with those from other studies of the Ridgecrest mainshock. We utilize seismic and GPS datasets to constrain the slip, which is similar to the approach by Liu et al. (2019). In contrast, other studies make use of a combination of seismic, high-rate GPS and InSAR (Ross et al., 2019; Chen et al., 2020; Goldberg et al., 2020), InSAR and optimal image tracking (Barnhart et al., 2019), or only seismic datasets (Zhang et al., 2020). The details of slip distribution, and in particular the relative location and amplitude of maximum slip, varies between studies. The maximum slip is mostly shallower ( $\sim 4 \mathrm{~km}$, Barnhart et al., 2019), to the northwest of ( $\sim 10 \mathrm{~km}$, Liu et al., 2019), or slightly deeper ( $\sim \mathrm{km}$, Ross et al., 2019) than the hypocenter location used in their inversion. The kinematic slip inversion we present resolves two primary slip patches (i.e., Fig. 1), which have similar amplitudes (4.7 and $2.5 \mathrm{~m}$ ) and locations (northwest and southeast of hypocenter)
Figure 3. $\triangle$ CFS of the mainshock on a receiver fault of $70^{\circ}$ strike and $90^{\circ}$ dip, approximating the leftmost part of the Garlock fault in this figure. (Top) $\Delta$ CFS results for a $5 \mathrm{~km}$ depth source at friction coefficients of (left to right) $0.2,0.4$, and 0.6 . (Bottom) $\Delta$ CFS results for a $10 \mathrm{~km}$ depth source with the same friction coefficients. The color version of this figure is available only in the electronic edition.

to the Barnhart et al. (2019), Liu et al. (2019), and Zhang et al. (2020) inversion results. A major difference in maximum slip amplitude occurs between our model and the Ross et al. (2019) study, which estimates as much as $9 \mathrm{~m}$ of slip between 5 and $10 \mathrm{~km}$ depth. Other notable changes between our study and other's include a more widely distributed higher $(>4 \mathrm{~m})$ slip distribution (Chen et al., 2020), or a maximum slip amplitude difference on the order of $1.5 \mathrm{~m}$ between what is resolved from our inversion (4.7 m) and the Goldberg et al. (2020) ( 3.5 m) study. Such differences are most likely due to the datasets used to constrain the inversions as well as the particular inversion parameterization. Overall, our mainshock slip distribution is consistent with other published models, characterized by bilateral rupture propagation and a shallow $(<10 \mathrm{~km})$ slip distribution.

\section{Static stress change}

We find the foreshock increased the $\triangle \mathrm{CFS}$ near the edges of the foreshock faults, especially at the intersection of plane 2 and mainshock fault, but our relocated mainshock hypocenter 
(a)

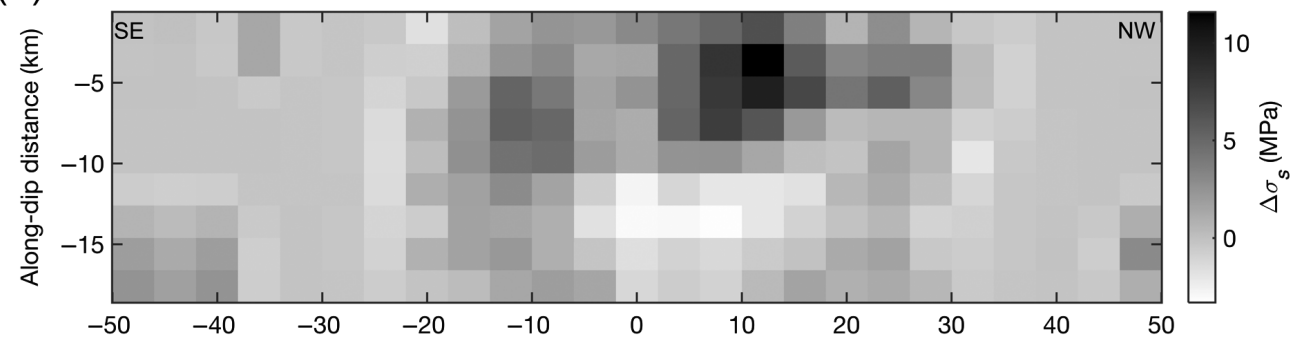

(b)

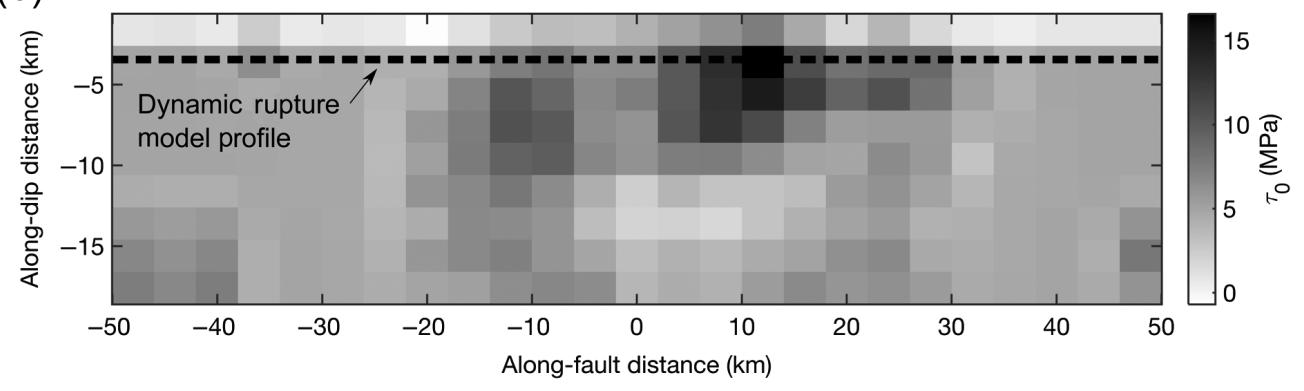

Figure 4. (a) Static stress drop and (b) initial shear stress along the mainshock fault plane. Static stress drop is calculated assuming a homogeneous Poisson medium and initial shear stress is computed using the complete stress-drop assumption. We select an initial shear stress profile through the main asperity at $3 \mathrm{~km}$ depth (dashed line) for our 2D dynamic rupture models. all friction coefficients that they tested. For a given friction coefficient, changing the depth of the $\triangle$ CFS calculation from 5 to $10 \mathrm{~km}$ increases the $\Delta C F S$ amplitude by $\sim 0.3 \mathrm{MPa}$ and decreases the extent of the region of positive $\triangle \mathrm{CFS}$ on the Garlock fault by approximately $20 \mathrm{~km}$ (Fig. 3). The amplitude difference is because the largest portion of mainshock slip extends to about $10 \mathrm{~km}$ depth, and the change in slip at this depth produces a larger $\triangle$ CFS than at $5 \mathrm{~km}$ depth. The region of positive $\Delta \mathrm{CFS}$ in proximity to the creeping section of the Garlock fault is most consistent in spatial extent with that of Barnhart et al. (2019) when we use a friction coefficient of 0.2 and a depth of $5 \mathrm{~km}$. Lastly, we find that the cluster of aftershocks on the Garlock fault are unlikely to be simply is located in a region of slightly decreased $\triangle$ CFS (Fig. 2a and Fig. S2). However, this result depends on the method used to locate the mainshock hypocenter and its uncertainty. For instance, the Advanced National Seismic System (ANSS) comprehensive catalog epicentral coordinates agree with ours to within a kilometer but its depth is $5 \mathrm{~km}$ deeper than our preferred depth of $3 \mathrm{~km}$, whereas the hypocenter resolved by Ross et al. (2019) is $\sim 12 \mathrm{~km}$ away from the foreshock hypocenter but at a similar shallow depth $(<4 \mathrm{~km})$. The hypocenters estimated by the ANSS catalog and by Ross et al. (2019) are located near the edges of different regions of positive $\triangle \mathrm{CFS}$. We also calculated the $\triangle$ CFS from both foreshock planes separately (Fig. $2 b$, c). Plane 2 has a much larger slip compared with plane 1, with almost twice the peak slip (i.e., 1.3 vs. $0.74 \mathrm{~m}$; Table 1). However, plane 1 causes an $\sim 0.5 \mathrm{MPa}$ greater $\Delta \mathrm{CFS}$ on the southeast region of the mainshock fault compared with plane 2, as plane 1 is closer (Fig. 2b). This underscores the sensitivities of the $\Delta$ CFS to input fault-slip amplitude and extent.

We further calculate the $\Delta$ CFS on the Garlock fault due to mainshock slip and assess the effect of various friction coefficients and depths on our results. Overall, we find that the friction coefficient has a relatively small (i.e., a difference within $\sim 0.1 \mathrm{MPa}$ ) impact on our $\Delta$ CFS results for a given depth (Fig. 3). Larger friction coefficients tend to increase the $\Delta \mathrm{CFS}$ amplitude and changes the spatial distribution of positive and negative stress changes (Fig. 3). This is similar to Barnhart et al. (2019), in which they found that their results are consistent for explained by $\triangle \mathrm{CFS}$ from the mainshock as the value of the stress change can be small $(<0.01 \mathrm{MPa})$ or even negative $(\sim-0.1 \mathrm{MPa})$ (Fig. 3).

\section{Dynamic earthquake rupture model}

Our first goal is to explain the kinematic fault-slip distribution using rupture dynamics. We seek to reproduce the two primary patches of 2.5 and $4.7 \mathrm{~m}$ slip southeast and northwest of the hypocenter, respectively, (Figs. $1 \mathrm{~b}$ and $5 \mathrm{a}$ ). We show the rupture history until $35 \mathrm{~s}$ to highlight the arrest of both the northwest and southeast rupture fronts (Fig. 5).

The initial conditions and friction parameters outlined in the Methodology section gives a good agreement between the kinematically imaged and dynamically modeled slip distributions. The exception is the region near the hypocenter, where the dynamic rupture model overpredicts the kinematic slip amplitude by $\sim 0.8 \mathrm{~m}$ (Fig. 5a). This is most likely due to our timeweakening nucleation procedure but is probably within the uncertainty of the true fault slip resolved by the kinematic inversion. The distribution in dynamic stress drop is positive for which higher slip is concentrated, and negative in a small region southeast of the hypocenter and where we impose slip-strengthening frictional behavior at the ends of the fault (Fig. 5b).

The bilateral mainshock dynamic rupture is overall heterogeneous and spatiotemporally complex (Fig. 5c). There are three major asperities (i.e., relatively high dynamic stress-drop regions) that contribute to several rupture-front accelerations (Fig. 5b,c). 
(a)

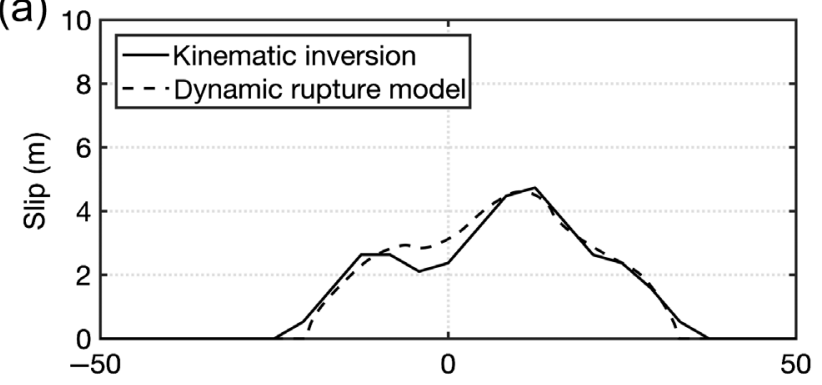

(b)

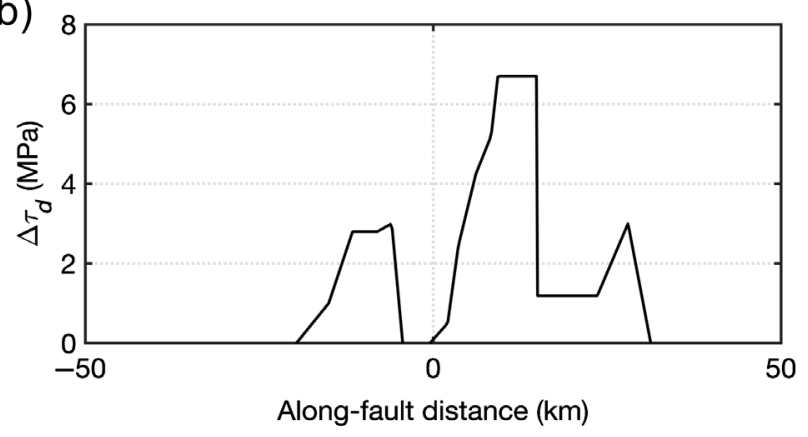

The model shows a slow $(<1 \mathrm{~km} / \mathrm{s})$ rupture front propagating to the southeast for the first $5 \mathrm{~s}$ after nucleation ceases; this southeast rupture front then accelerates to $\sim 1.3 \mathrm{~km} / \mathrm{s}$ before decelerating and arresting at $28 \mathrm{~s}$ (Fig. 5c). In contrast, the northwest rupture front propagates at a more uniform speed $(\sim 2.1 \mathrm{~km} / \mathrm{s})$ before decelerating and stopping at $\sim 25 \mathrm{~s}$. These rupture speeds are consistent with recent kinematic models that prescribe a constant sub-Rayleigh mainshock rupture speed (Liu et al., 2019; Ross et al., 2019; Goldberg et al., 2020; Zhang et al., 2020). Rupture speed depends on how much total available energy is partitioned into radiated or fracture energy during the faulting process. Slower ruptures (as observed during the Ridgecrest sequence) may be due to a relatively high fracture energy consumed on the fault, consistent with the hypothesis that the Llfz is less compliant and more energy was needed to break multiple fault segments (Perrin et al., 2016; Liu et al., 2019; Goldberg et al., 2020). Our dynamic model shows that the mainshock rupture fronts do not exhibit slip-rate amplitudes above $4 \mathrm{~m} / \mathrm{s}$ and propagate at well below the Rayleigh wavespeed.

\section{Temporal stress changes on the Garlock fault}

Using our dynamic rupture model, we investigate the stress contributions to a section of the central Garlock fault during and after the Ridgecrest mainshock. Given the limitation of our modeling domain, we cannot assess far-field dynamic stress contributions from surface-wave amplitude changes. We instead focus on how the initial peak stresses carried by near-field seismic waves impacted the Garlock fault during coseismic rupture.

The 2D stress tensor in our model is for an isotropic body and yields three unique components: $\sigma_{x x}, \sigma_{y y}$, and $\sigma_{x y}$. Only (c)

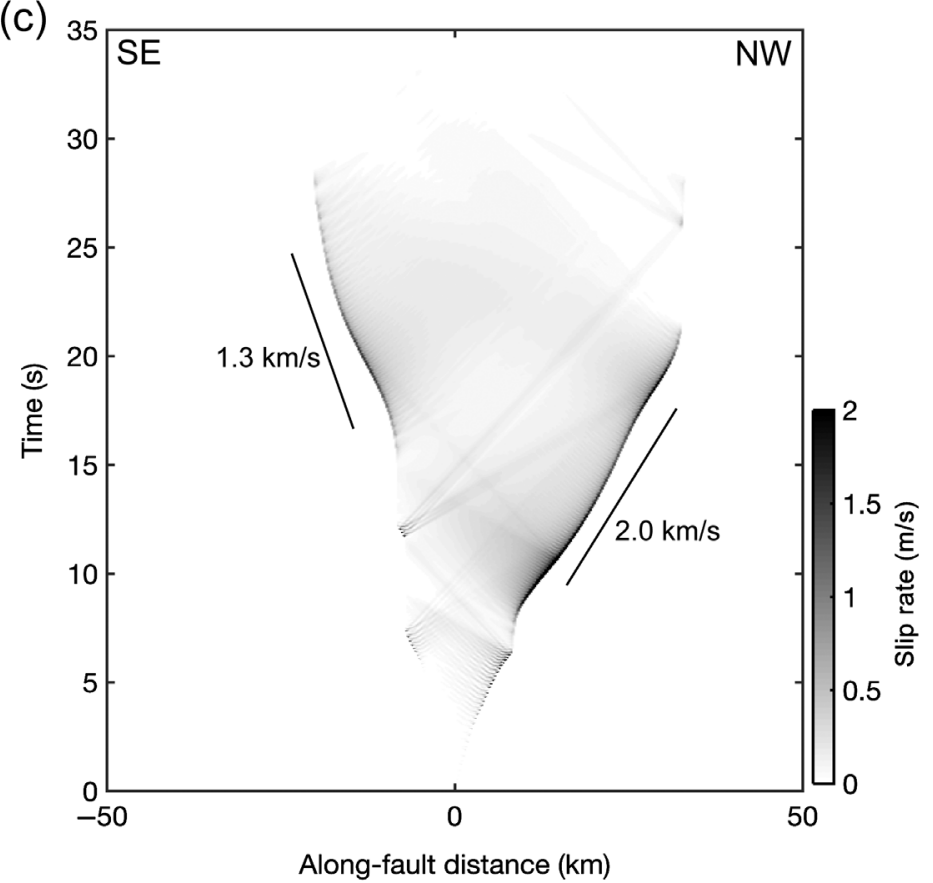

Figure 5. (a) Along-fault slip distribution resolved by the kinematic slip inversion (solid line) and that calculated from the dynamic rupture model (dashed line). The $x$-axis measures distance from where the earthquake is nucleated in our model. (b) Dynamic stress drop along the fault. Location shown in Figure 4. (c) Spatiotemporal and bilateral rupture history predicted by the dynamic rupture model. Solid lines signify average rupture-front speed. Both rupture fronts propagate at sub-Rayleigh wavespeed.

one component of the normal stress $\left(\sigma_{y y}\right)$ and the shear stress $\left(\sigma_{x y}\right)$ are important to be considered further in our analysis. If we place the strike of the mainshock fault plane on an east-west coordinate system, the angle between the mainshock and Garlock fault planes (measured clockwise) is approximately $110^{\circ}$. We therefore applied a rotation of the stress field at a particular instant in time to represent the stress perturbation the mainshock imparts to the Garlock fault (Fig. 6; see the supplemental material). When this rotation is performed at the final timestep, the rotated stress field is equivalent to the static stress change on the Garlock fault. We observe an abrupt transition from negative to positive normal static stress change as one crosses the intersection of the strike of the mainshock fault plane (Fig. 7a). The shear stress change is slightly more complex with an asymmetric stress amplitude distribution across the fault, but shows a very pronounced region of positive stress change that generally coincides with the $\sim 25$-kilometer-long section of the central Garlock fault that underwent creep (Fig. 7b; Barnhart et al., 2019; Xu et al., 2020). To confirm our static stress-change analysis from the dynamic model, we compare it with our $\triangle \mathrm{CFS}$ calculation and find that its orientation and amplitude are consistent (Fig. S4). 

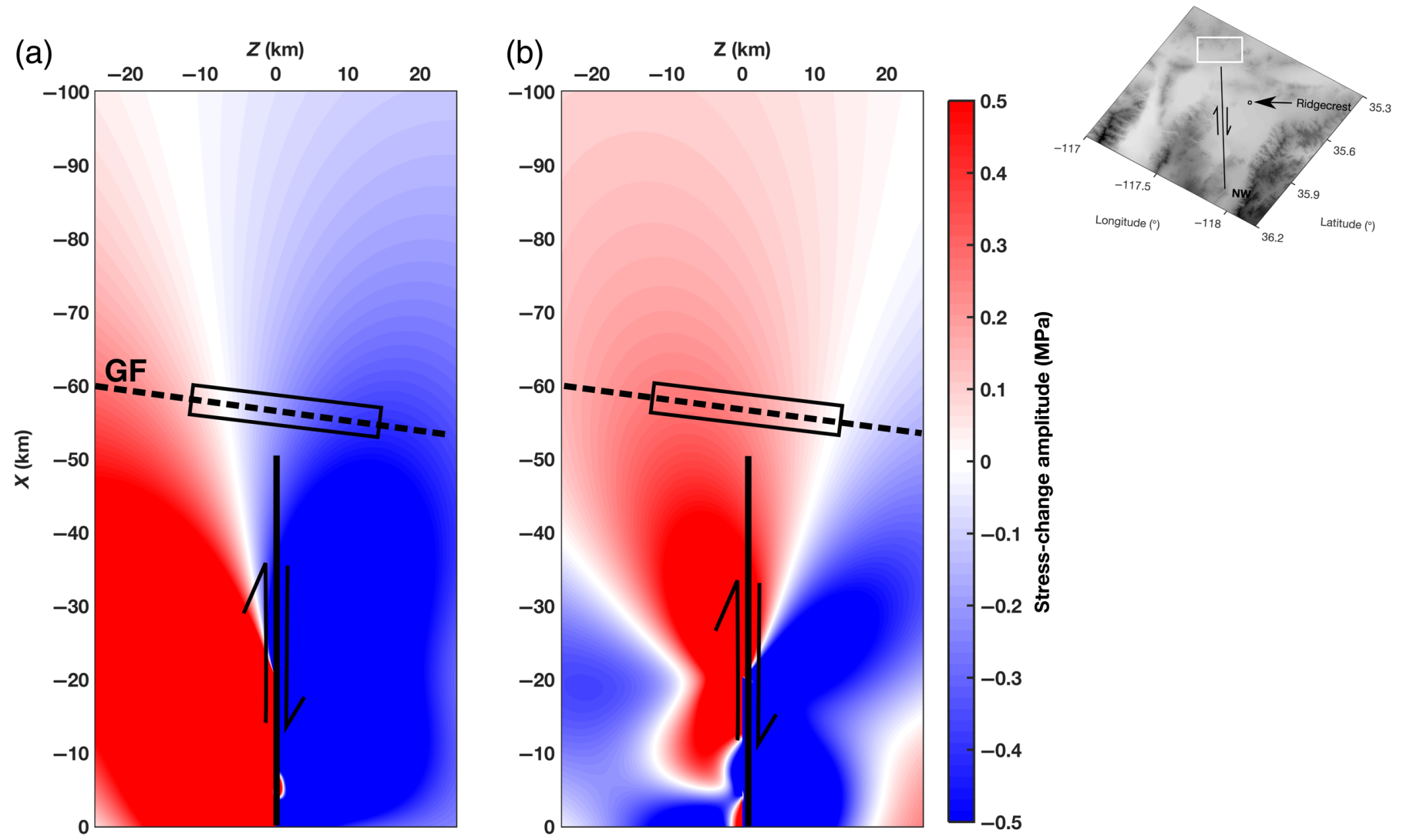

We also calculate the temporal stress change on the central Garlock fault segment during the Ridgecrest mainshock. We select one point near the creeping region on the Garlock fault $(-60 \mathrm{~km},-10 \mathrm{~km}$; Figs. 7 and 8$)$ to show how normal and shear stresses change during mainshock rupture. Although propagation spontaneously arrests at near $\sim 28 \mathrm{~s}$ toward the southeast, we simulate rupture until $100 \mathrm{~s}$ to make sure stress changes relax to constant levels, which are attained at $60 \mathrm{~s}$ (Fig. 9). This section of the central Garlock fault begins to experience a positive normal stress change near $17.5 \mathrm{~s}$ (Fig. 7). During the main portion of coseismic rupture, normal stress changes reach their maximum of $\sim 0.3 \mathrm{MPa}$ at $32 \mathrm{~s}$ (Figs. $7 \mathrm{f}$ and $9 \mathrm{a}$ ). In contrast, positive shear stress changes arrive at the Garlock fault in three distinct pulses (e.g., Figs. $8 \mathrm{f}$ and 9a). Two of these positive shear stress-change pulses arrive after the largest change in normal stress change and continue to be above the normal stress-change amplitude for the remainder of our simulation (Figs. 8 and 9a). The extrema of the normal and shear stress-change amplitudes are symmetric through time due to the alternating arrivals of compressional-wave $(P)$ and shear-wave $(S V)$ motions.

\section{DISCUSSION AND CONCLUSION}

We show that stress changes during and after the Ridgecrest foreshocks and mainshock may have influenced postseismic creep on the central Garlock fault segment and brought certain
Figure 6. Static stress-change field in the modeling domain rotated to the strike of the Garlock fault. (a) Normal stress and (b) shear stress. Garlock fault trace (dashed line) and Ridgecrest mainshock fault (solid line) are superimposed onto the figure. Box denotes approximate location of the creeping region (Barnhart et al., 2019). Inset study area map gives stresschange spatial orientation for Figures $6-8$. The color version of this figure is available only in the electronic edition.

regions potentially closer to coseismic failure. Our results also shed light on the temporal stress evolution on the Garlock fault due to source dynamics. Because both normal and shear stresses vary during coseismic rupture, evaluating their respective contribution is of critical importance to identifying periods when stress changes may have been favorable to engender the observed postseismic creep.

The $\Delta$ CFS results show that positive static stress changes were experienced on the central Garlock fault due to mainshock slip (Fig. 3) and are coincident with previously documented fault creep (Barnhart et al., 2019; Ross et al., 2019; $\mathrm{Xu}$ et al., 2020). Among $\Delta \mathrm{CFSs}$ calculated for different friction levels and depths, in only one case (i.e., friction level of 0.6) is a positive static stress change on the order of $\sim 0.1 \mathrm{MPa}$ observed adjacent to the region of the Garlock fault that experienced a sizeable aftershock swarm (Fig. 3). This may indicate that other postseismic relaxation processes or dynamic stress changes 
(a)

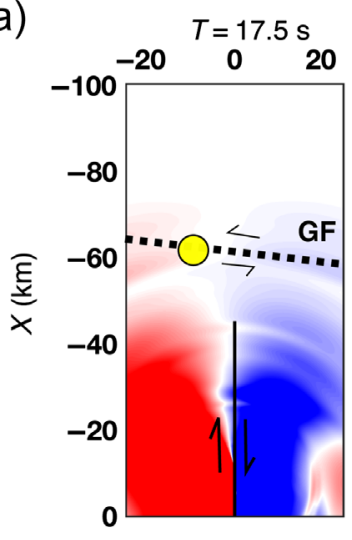

(c)

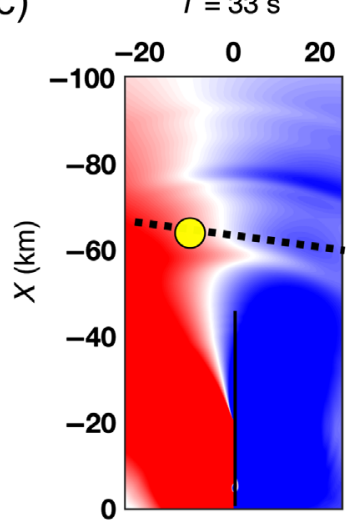

(e)

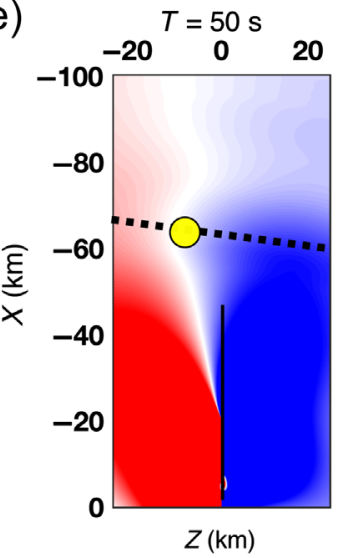

(b)

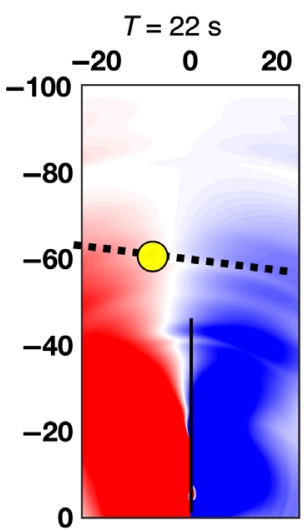

(d)

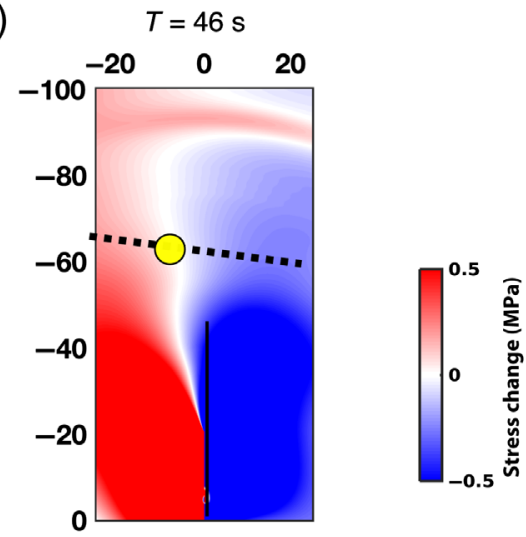

(f)

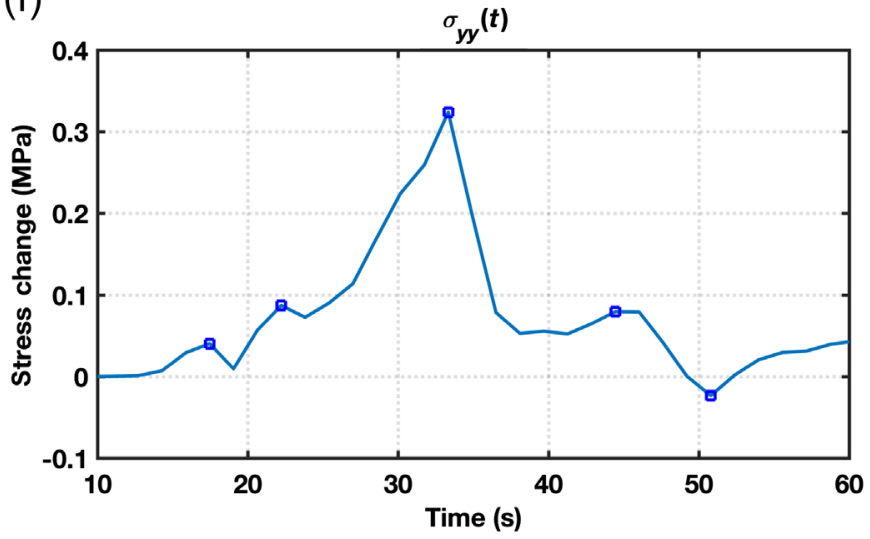

$\triangle \mathrm{CFS}$ at the location of our hypocenter. The disparity in magnitude and sign of the results may be due to the fact that Coulomb stress calculations are very sensitive to the slip-inversion model used and the inferences may change depending on the location of the hypocenter, as well.

When we assess the $\triangle \mathrm{CFS}$ through time we find that $\Delta$ CFS predominantly increases during mainshock rupture and remains at a high level afterward; this is evident from our dynamic model as the normal stress-change amplitude is mostly below the shear stress amplitude (Fig. 9b). Temporal stress changes during the mainshock rupture also support predominantly positive shear stress changes near this creeping Garlock region (Fig. 8), whereas positive and negative normal stress distributions are observed on both sides of the projected intersection of the mainshock and Garlock fault planes (Fig. 7). Our results for temporal normal and shear stress changes near the Garlock fault agree with other dynamic rupture simulations that prescribe a complex 3D fault geometry but similar constitutive friction law parameters (Lozos and Harris, 2020). Moreover, this study also documents a detailed temporal evolution of normal, shear, and Coulomb stresses impacting the central Garlock fault (i.e., Fig. 9), and not just the final stress changes after all seismic waves have been

Figure 7. Normal stress changes $\left(\sigma_{y y}\right)$ at various moments in time on the central Garlock fault during coseismic rupture of the mainshock. A point on the Garlock is selected to visualize the stress amplitude variability (solid circle). (a-e) represent $\sigma_{y y}$ from 17.5 to $50 \mathrm{~s}$ during rupture propagation. (f) The time history of $\sigma_{y y}$ in which (a-e) the blue squares denote the amplitude change at each of the normal stress snapshots. The color version of this figure is available only in the electronic edition.

were at play to produce this aftershock pattern. Various studies have also calculated the $\triangle \mathrm{CFS}$ of the foreshock at the mainshock hypocenter with their slip-inversion results. While Barnhart et al. (2019) found an increase in $\triangle \mathrm{CFS}$ of $0.6 \mathrm{MPa}$ due to the foreshock at their hypocenter, Zhang et al. (2020) found an increase of $0.04 \mathrm{MPa}$ and Goldberg et al. (2020) found a $<0.1 \mathrm{MPa}$ increase. We find a $0.1 \mathrm{MPa}$ decrease in radiated away. Because positive normal stress changes serve to strengthen the fault whereas positive shear stresses should bring the fault closer to failure, our dynamic model offers one possible scenario that creep could have occurred as soon as $\sim 15 \mathrm{~s}$ after nucleation of the Ridgecrest mainshock when positive shear stresses began to arrive at the Garlock fault. However, this is speculative given that we do not have information on the 
(a)

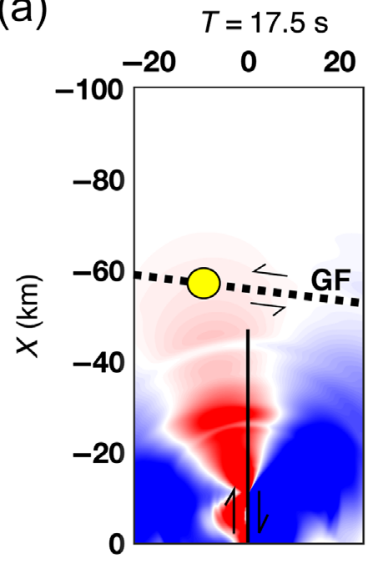

(c)

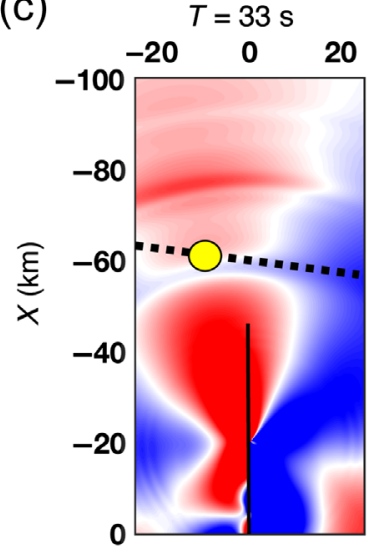

(e)

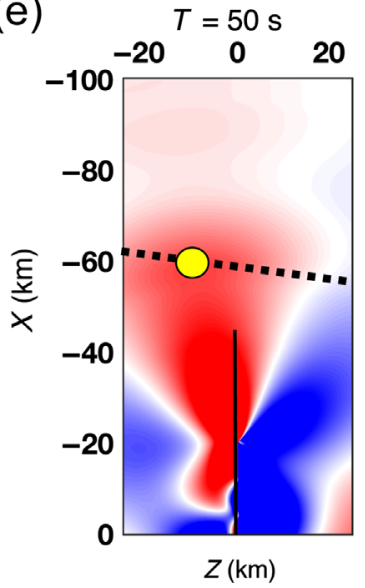

(b)

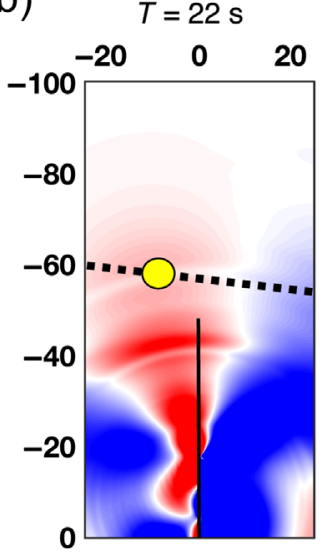

(d)

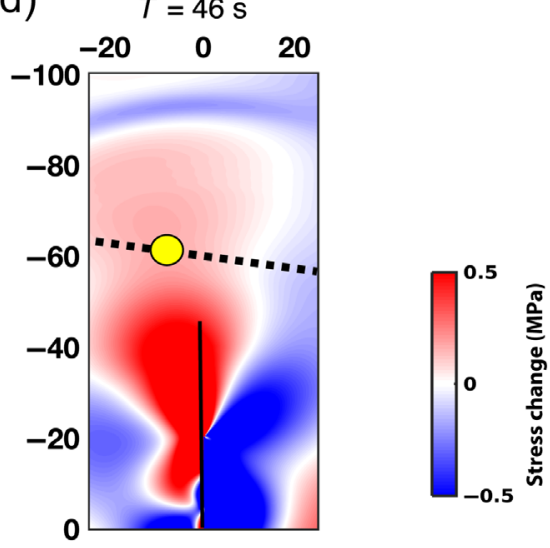

(f)

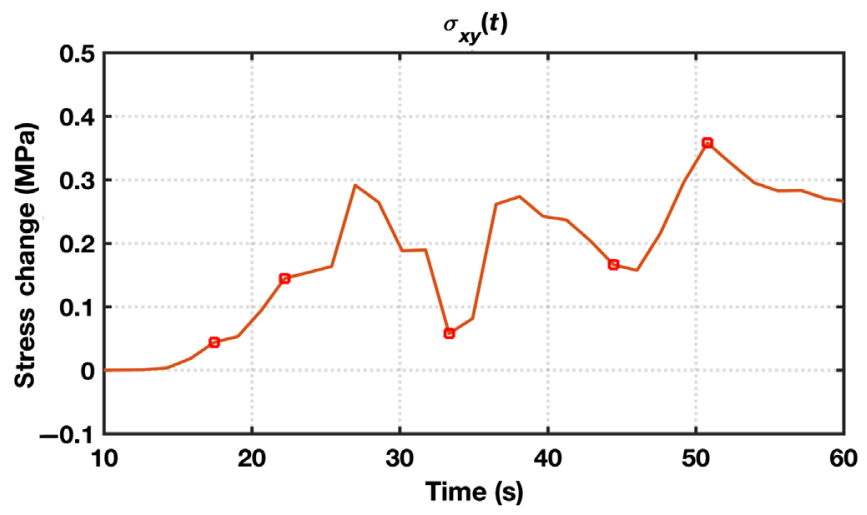

Figure 8. Similar to Figure 9 , but shear stress changes $\left(\sigma_{x y}\right)$ during coseismic rupture. (a-e) $\sigma_{x y}$ from 17.5 to $50 \mathrm{~s}$ during rupture propagation. (f) The time history of $\sigma_{x y}$ showing three distinct peaks in stress change on the Garlock fault at $\sim 28,38$, and $50 \mathrm{~s}$. The color version of this figure is available only in the electronic edition.

absolute stress state of the Garlock fault prior to the aftershock and mainshock sequence.

Our dynamic model also suggests that the largest shear stress changes (0.3-0.4 MPa) arrived before and after the largest normal stress changes, but they are comparable in amplitude (Figs. 7-9a). Given this maximum shear stress-change amplitude at a given time, we estimate approximately
$0.1 \mathrm{~cm}$ of slip may have been triggered near the creeping section of the Garlock fault at a depth less than $1 \mathrm{~km}$ (Fig. S5a). We also test a model for which creep on the Garlock fault was exceptionally shallow (<300 m depth; Schleicher et al., 2019), but the distribution of creep is more heterogeneous. We still obtain a similar amount of creep that is consistent with the shear stress-change amplitude (Fig. S5b). These estimates are lower than the maximum magnitude of resolved surface creep (i.e., $\sim 3 \mathrm{~cm}$ ) documented earlier by Barnhart et al. (2019) and Ross et al. (2019), however. The creep magnitudes we estimate are furthermore only valid for a homogenous, Poisson solid and should be considered an upper bound for any given shear stress-change perturbation because our dynamic rupture model captures the region on the mainshock fault plane that experiences the greatest dynamic stress drop ( 7 MPa; Fig. 5b). There is potential for more creep to be accommodated by successive near-field stress changes arriving at the Garlock fault during mainshock rupture, but this depends on the near-surface rheology and earthquake history of the central Garlock fault. In addition, we cannot rule out the possibility that the maximum resolvable creep was driven by cumulative or postseismic strain-rate changes not seen by satellite observations because the smallest observation window is at least five to six days after the mainshock (Barnhart et al., 2019). But extensometer data imply that it did not extend very deep into the crust, regardless of how much triggered creep was (Bilham and Castillo, 2020).

The fact that the Garlock fault did not coseismically fail could be supported by theoretical considerations to the 
(a)

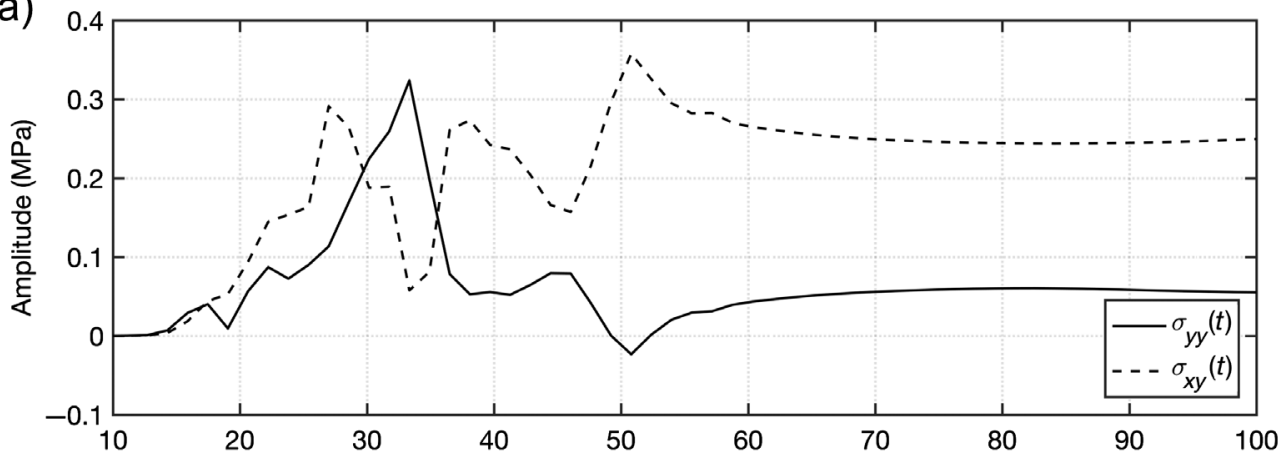

(b)

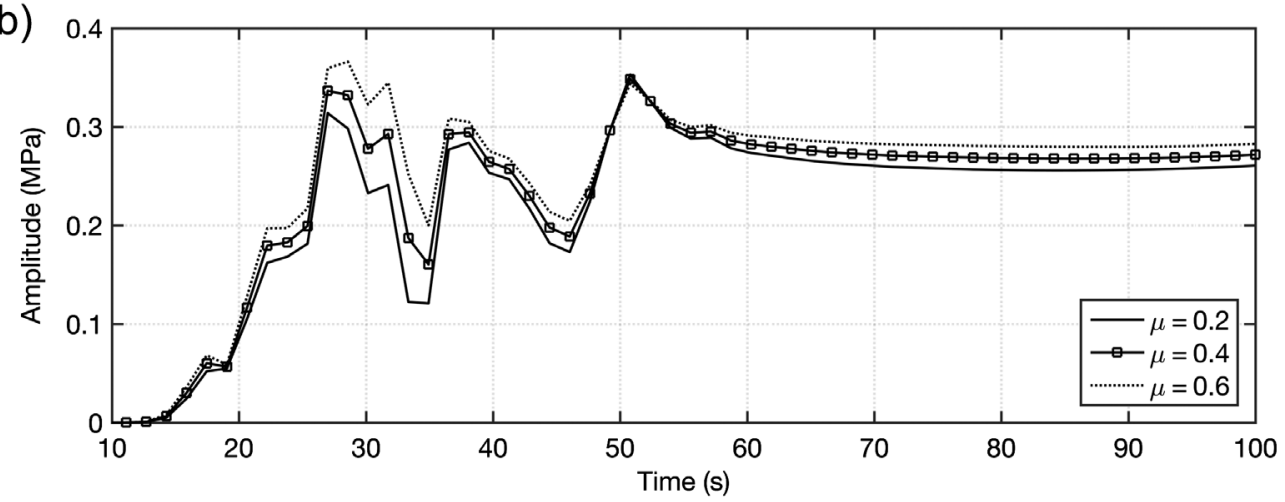

Figure 9. Stress-change evolution on a section of the Garlock fault during the entire Ridgecrest earthquake simulation. (a) Normal $\left(\sigma_{y y}\right)$ and shear $\left(\sigma_{x y}\right)$ stress change. (b) Temporal $\Delta$ CFS for friction coefficient levels assessed in the static stress-change analysis. Note that we plot the temporal stress change starting at $10 \mathrm{~s}$ because this is when the nucleation procedure ceases.

SH_max orientation to the mainshock fault plane, and perhaps lend credence to theoretical expectations we have briefly discussed here.

One aspect we could continue to explore in greater detail is how a fully dynamic model incorporating segmented foreshock and mainshock fault planes changes the details of the temporal stress changes on the Garlock fault. Several kinematic studies are able to fit seismogeodetic data using a segmented fault model (e.g., Liu et al., 2019; Ross et al., 2019; Goldberg et al., 2020). Given that the Ridgecrest sequence produced multiple orthogonal faulting with some ruptures breaking the surface while others did not (Ross et al., 2019), we would expect the temporal stress change to accordingly reflect this complexity. We note that the geometrically segmented 3D dynamic fault model by Lozos and Harris (2020) yields static

prestress state, rupture speed and fault orientation between the mainshock and Garlock fault planes, if they are connected (Poliakov et al., 2002; Kame et al., 2003). For a low angle of maximum horizontal shear stress (SH_max) with respect to the fault $\left(<45^{\circ}\right)$, this prestress state encourages rupture to bifurcate toward the compressional side, whereas a higher angle $\left(>45^{\circ}\right)$ predicts that the rupture along the extensional side is more favorable (Poliakov et al., 2002). Yang and Hauksson (2013) inverted earthquake focal mechanisms in central and southern California, estimating the regional SH_max orientation lies between $0^{\circ}$ and $5^{\circ}$ east of north. Our dynamic rupture model predicts an average mainshock rupture-front speed to shear-wavespeed ratio of 0.4. Given that the mainshock fault plane is approximately oriented $45^{\circ}$ west of north, such a low prestress orientation together with low rupture speed levels are not likely to encourage rupture propagation to the Garlock fault, if connected (Kame et al., 2003). This mechanical argument, however, must be taken with a grain of salt considering changes in the local stress field orientation surrounding the $M_{\mathrm{w}} 7.1$ mainshock due to the $M_{\mathrm{w}} 6.4$, smaller foreshocks, and other seismicity. A detailed seismological analysis of foreshock and aftershock stress-tensor inversions will undoubtedly place stronger constraints on the normal and shear stress changes on the Garlock fault that are consistent to the first order in sign and amplitude with our modeling efforts. There are small differences, but this is expected due to different initial stress parameterizations, velocity structure, and fault geometry for the mainshock and foreshock fault planes.

How the $M_{\mathrm{w}} 6.4$ foreshock and $M_{\mathrm{w}} 7.1$ mainshock Ridgecrest sequences changed the local stress field in southern California is a crucial question to consider given the proximity of these events to other active faults (e.g., Garlock and San Andreas). Through a unique combination of kinematic, static, and dynamic modeling, we present a physically coherent picture of the stress changes on the central Garlock fault during and after the coseismic rupture of the $M_{\mathrm{w}} 7.1$ event. We find that positive stress changes near the creeping section of the Garlock fault are observed during and after coseismic rupture. We also show that the greatest shear stress change was comparable to the greatest normal stress change but arrived earlier during dynamic rupture; this may have promoted a section of the Garlock fault to creep even before the Ridgecrest mainshock finished slipping. Our dynamic models physically explain the resolved slip amplitude through the mainshock hypocenter and reproduce the low sub-Rayleigh rupture speeds previously suggested by kinematic rupture models. 


\section{DATA AND RESOURCES}

Static stress calculations are conducted using the Coulomb 3 software available from the U.S. Geological Survey (USGS) website (https:// earthquake.usgs.gov/research/software/coulomb/). All codes used in dynamic model postprocessing and figure creation as well as model input and output files are archived and freely accessible on University of Michigan (UM) Deep Blue (https://deepblue.lib.umich.edu/). All websites were last accessed in November 2019. Data used in the kinematic inversion are available upon request to Shengji Wei (shjwei@ ntu.edu.sg). Some figures in this article were generated with MATLAB software or used colormap schemes from Crameri (2018, doi: 10.5281/ zenodo.1243862). Supplemental material provides information on how we rotate stresses to the Garlock fault and show additional stress-change calculations.

\section{ACKNOWLEDGMENTS}

The authors thank Guest Editor Zachary Ross and two anonymous reviewers for their constructive comments that improved this article. This study was supported by the University of Michigan. M. D. Ramos, J. C. Neo, P. Thakur, and Y. Huang acknowledge the funding support from the National Science Foundation through Grant Awards 1663769 and 1943742. M. D. Ramos thanks P. M. Mai for providing a computationally efficient algorithm for static stress change on faults due to kinematic slip.

\section{REFERENCES}

Allen, C. R., M. Wyss, J. N. Brune, A. Grantz, and R. E. Wallace (1972). Displacements on the imperial, Superstition Hills, and San Andreas faults triggered by the Borrego Mountain earthquake, in The Borrego Mountain Earthquake of April 9, 1968, U.S. Geol. Surv. Profess. Pap. 787, 87-104.

Ampuero, J. P. (2009). SEM2DPACK: A spectral element method tool for $2 \mathrm{D}$ wave propagation and earthquake source dynamics, User's Guide, version 2.3.6, Retrieved from http://www.sourceforge.net/ projects/sem2d/ (last accessed September 2017).

Andrews, D. J. (1985). Dynamic plane-strain shear rupture with a slipweakening friction law calculated by a boundary integral method, Bull. Seismol. Soc. Am. 75, no. 1, 1-21.

Astiz, L., and C. R. Allen (1983). Seismicity of the Garlock fault, California, Bull. Seismol. Soc. Am. 73, no. 6, 1721-1734.

Barnhart, W. D., G. P. Hayes, and R. D. Gold (2019). The July 2019 Ridgecrest, California, earthquake sequence: Kinematics of slip and stressing in cross-fault ruptures, Geophys. Res. Lett. 46, 11,85911,867, doi: 10.1029/2019GL084741.

Bilham, R., and B. Castillo (2020). The July 2019 Ridgecrest, California, earthquake sequence recorded by creepmeters: Negligible epicentral afterslip and prolonged triggered slip at teleseismic distances, Seismol. Res. Lett. 91, 707-720, doi: 10.1785/0220190293.

Bodin, P., and J. Gomberg (1994). Triggered seismicity and deformation between the Landers, California, and Little Skull Mountain, Nevada, earthquakes, Bull. Seismol. Soc. Am. 84, no. 3, 835-843.

Brodsky, E. E., J. J. Mori, L. Anderson, F. M. Chester, M. Conin, E. M. Dunham, N. Eguchi, P. M. Fulton, R. Hino, T. Hirose, et al. (2020). The state of stress on the fault before, during, and after a major earthquake, Annu. Rev. Earth Planet. Sci. 48, no. 1, doi: 10.1146/ annurev-earth-053018-060507.
Crameri, F. (2018). Scientific colour-maps, Zenodo. doi: 10.5281/zenodo.1243862.

Chen, K., J. P. Avouac, S. Aati, C. Milliner, F. Zheng, and C. Shi (2020). Cascading and pulse-like ruptures during the 2019 Ridgecrest earthquakes in the Eastern California shear zone, Nat. Commun. 11, no. 1, 3-10, doi: 10.1038/s41467-019-13750-w.

Dawson, T. E., S. F. McGill, and T. K. Rockwell (2003). Irregular recurrence of paleoearthquakes along the central Garlock fault near El Paso Peaks, California, J. Geophys. Res. 108, no. B7, doi: 10.1029/2001jb001744.

Davis, G. A., and B. C. Burchfiel (1973). Garlock fault: An intracontinental transform structure, Southern California, Geol. Soc. Am. Bull. 84, 1407-1422.

Goldberg, D. E., D. Melgar, V. J. Sahakian, A. M. Thomas, X. Xu, B. W. Crowell, and J. Geng (2020). Complex rupture of an immature fault zone: A simultaneous kinematic model of the 2019 Ridgecrest, CA earthquakes, Geophys. Res. Lett. 47, no. 3, doi: 10.1029/2019GL086382.

Hill, M. L., and T. W. Dibblee (1953). San Andreas, Garlock and Big Pine faults, California, Bull. Geol. Soc. Am. 64, 443-458.

Ji, C., D. J. Wald, and D. V. Helmberger (2002). Source description of the 1999 Hector Mine, California earthquake; part I: Wavelet domain inversion theory and resolution analysis, Bull. Seismol. Soc. Am. 92, no. 4, 1192-1207.

Kame, N., J. R. Rice, and R. Dmowska (2003). Effects of prestress state and rupture velocity on dynamic fault branching, J. Geophys. Res. 108, no. B5, doi: 10.1029/2002jb002189.

Lienkaemper, J. J., J. S. Galehouse, and R. W. Simpson (1997). Creep response of the Hayward fault to stress changes caused by the Loma Prieta earthquake, Science 276, no. 5321, 2014-2016, doi: 10.1126/science.276.5321.2014.

Lin, J., and R. S. Stein (2004). Stress triggering in thrust and subduction earthquakes, and stress interaction between the southern San Andreas and nearby thrust and strike-slip faults, J. Geophys. Res. 109, no. B02303, doi: 10.1029/2003JB002607.

Liu, C., T. Lay, E. E. Brodsky, K. Dascher-Cousineau, and X. Xiong (2019). Coseismic rupture process of the large 2019 Ridgecrest earthquakes from joint inversion of geodetic and seismological observations, Geophys. Res. Lett. 46, doi: 10.1029/2019GL084949.

Lozos, J. C., and R. A. Harris (2020). Dynamic rupture simulations of the M6.4 and M7.1 July, 2019 Ridgecrest, California earthquakes, Geophys. Res. Lett. 47, doi: 10.1029/2019GL086020.

Ma, S., and R. J. Archuleta (2006). Radiated seismic energy based on dynamic rupture models of faulting, J. Geophys. Res. 111, doi: 10.1029/2005JB004055.

Madugo, C. M., J. F. Dolan, and R. D. Hartleb (2012). New paleoearthquake ages from the western Garlock fault: Implications for regional earthquake occurrence in Southern California, Bull. Seismol. Soc. Am. 102, no. 6, 2282-2299, doi: 10.1785/0120110310.

McGill, S. F., and K. Sieh (1991). Surficial offsets on the central and eastern Garlock fault associated with prehistoric earthquakes, J. Geophys. Res. 96, 21,597-21,621.

Noda, H., and N. Lapusta (2013). Stable creeping fault segments can become destructive as a result of dynamic weakening, Nature 493, 518-521, doi: 10.1038/nature11703.

Perrin, C., I. Manighetti, J.-P. Ampuero, F. Cappa, and Y. Gaudemer (2016). Location of largest earthquake slip and fast rupture 
controlled by along-strike change in fault structural maturity due to fault growth, J. Geophys. Res. 121, no. 5, 3666-3685, doi: 10.1002/2015JB012671.

Poliakov, A. N. B., R. Dmowska, and J. R. Rice (2002). Dynamic shear rupture interactions with fault bends and off-axis secondary faulting, J. Geophys. Res. 107, no. B11, ESE 6-1-ESE 6-18, doi: 10.1029/ $2001 \mathrm{jb} 000572$.

Rice, J. R. (1992). Fault stress states, pore pressure distributions, and the weakness of the San Andreas Fault, Int. Geophys. 51 (C), 475-503, doi: 10.1016/S0074-6142(08)62835-1.

Ripperger, J., and P. M. Mai (2004). Fast computation of static stress changes on 2D faults from final slip distributions, Geophys. Res. Lett. 31, no. 18, 2-5, doi: 10.1029/2004GL020594.

Ross, Z. E., B. Idini, Z. Jia, O. L. Stephenson, M. Zhong, X. Wang, Z. Zhan, M. Simons, E. J. Fielding, S.-H. Yun, et al. (2019). 2019 Ridgecrest earthquake sequence, Science 3665, October, 346-351.

Schleicher, L. S., M. Huang, K. L. Allison, and R. J. Anderson (2019). Seismic hazard implications of post-seismic deformation and stress transfer from the 2019 Searles Valley California earthquakes, presented at the 2019 Fall Meeting, AGU, San Francisco, California, 9-14 December 2019, Abstract S41C-08.

Tinti, E., M. Cocco, E. Fukuyama, and A. Piatanesi (2009). Dependence of slip weakening distance $\left(D_{c}\right)$ on final slip during dynamic rupture of earthquakes, Geophys. J. Int. 177, no. 3, 1205-1220, doi: 10.1111/j.1365-246X.2009.04143.x.

Toda, S., R. S. Stein, K. Richards-Dinger, and S. Bozkurt (2005). Forecasting the evolution of seismicity in southern California: Animations built on earthquake stress transfer, J. Geophys. Res. 110, no. B05S16, doi: 10.1029/2004JB003415.

$\mathrm{Xu}, \mathrm{X}$. , D. T. Sandwell, and B. Smith-Konter (2020). Coseismic displacements and surface fractures from Sentinel-1 InSAR: 2019 Ridgecrest earthquakes, Seismol. Res. Lett. doi: 10.1785/ 0220190275.

Yang, W., and E. Hauksson (2013). The tectonic crustal stress field and style of faulting along the Pacific North America Plate boundary in Southern California, Geophys. J. Int. 194, 100-117, doi: 10.1093/gji/ggt113.

Zhang, Y., X. Zheng, Q. Chen, X. Liu, X. Huang, Y. Yang, Q. Xu, and J. Zhao (2020). Automatic inversion of rupture processes of the foreshock and mainshock and correlation of the seismicity during the 2019 Ridgecrest earthquake sequence, Seismol. Res. Lett. 91, 1556-1566, doi: 10.1785/0220190343.

Manuscript received 17 January 2020

Published online 9 June 2020 